\title{
Health-related quality of life measured using the EQ-5D-5 L: population norms for the capital of Iran
}

\author{
Zahra Emrani ${ }^{1}$, Ali Akbari Sari ${ }^{1}$, Hojjat Zeraati ${ }^{2}$, Alireza Olyaeemanesh ${ }^{3}$ and Rajabali Daroudi ${ }^{{ }^{*}}$ (D)
}

\begin{abstract}
Objectives: $E Q-5 D$ is the most commonly used generic preference-based health-related quality of life (HRQoL) measure. The current study aimed at estimating the HRQoL index scores using EQ-5D-5 L measure in the capital of Iran; moreover, identifying some determinants of the HRQOL.

Methods: A sample of 3060 subjects was selected by a stratified random sampling method from the general adult population of Tehran. Face-to-face interview was conducted to fill out the questionnaire, in this cross-sectional survey. EQ-5D-5 L utility score were estimated using an interim value set, based on a crosswalk methodology. Additionally, the relationships between HRQoL and sociodemographic characteristics were tested by generalized linear model, using STATA version 13.

Results: The mean \pm standard deviation utility and EQ-VAS scores were $0.79 \pm 0.17$ and $71.72 \pm 19.37$. The utility scores ranged $0.61 \pm 0.19$ in > 69 year-old females to $0.88 \pm 0.12$ in < 30 year-old males. In mobility, self-care, and usual activity dimensions, most of the respondents reported "no problems" (70.47, 90.62, and 76.34\%, respectively). However, in anxiety/depression and pain/discomfort dimensions, most of the respondents had problems (53.23 and $54.03 \%$, respectively). Females had lower utility score than males; the utility score reduced with age increase; the educational level lead to higher utility scores; and the utility scores of individuals without spouse (divorced or widowed) were lower than those of the married individuals and never married ones.

Conclusions: The current study reported HRQoL norm data for the general adult population in the capital of Iran; these data could be very useful for policy making and economic evaluations. A significant percentage of people in Tehran reported anxiety/ depression, which highlights the risk of psychological problems. Effective interventions are needed to increase their HRQoL, especially for the vulnerable groups of the community.
\end{abstract}

Keywords: EQ-5D, Health related quality of life, Utility score, Iran

\section{Introduction}

Nowadays, Health-related quality of life (HRQoL) has become an important health outcome indicator, and it is considered a primary outcome in many clinical trials [1]. HRQoL focuses on factors that are part of the person's

\footnotetext{
* Correspondence: rdaroudi@sina.tums.ac.ir

'Department of Health Management and Economics, School of Public Health, Tehran University of Medical Sciences, Poursina Ave, Tehran 1417613191, Iran

Full list of author information is available at the end of the article
}

health (well-being and functioning) [1]. Different instruments are developed to measure HRQoL. Some of them are disease specific (e g, St George's asthma quality of life scale, NEWQOL-6D, EORTC QOL-30), while some are generic (e g, EQ-5D, SF-6D, WHOQOL) [2].

The EuroQol five-dimensional (EQ-5D) is a very popular generic and preference-based instrument to make index values and health profiles [1]. It is a multiattribute instrument, which considers five dimensions

(C) The Author(s). 2020 Open Access This article is licensed under a Creative Commons Attribution 4.0 International License, which permits use, sharing, adaptation, distribution and reproduction in any medium or format, as long as you give appropriate credit to the original author(s) and the source, provide a link to the Creative Commons licence, and indicate if changes were made. The images or other third party material in this article are included in the article's Creative Commons licence, unless indicated otherwise in a credit line to the material. If material is not included in the article's Creative Commons licence and your intended use is not permitted by statutory regulation or exceeds the permitted use, you will need to obtain permission directly from the copyright holder. To view a copy of this licence, visit http://creativecommons.org/licenses/by/4.0/ The Creative Commons Public Domain Dedication waiver (http://creativecommons.org/publicdomain/zero/1.0/) applies to the data made available in this article, unless otherwise stated in a credit line to the data. 
including mobility, self-care, usual activities, pain/discomfort, and anxiety/depression. There are two versions of EQ-5D [3]. In three-level version $243\left(3^{5}\right)$ health states are derived from the sample to establish a utility weight system. Levels are "no problems, some problems, and severe problems". Many studies reported measurement insensitivity [4] and ceiling effect [5-7] about EQ-5D-3 L questionnaire. These issues are resolved to some extent in the new version. In five level version of EQ-5D the levels changed to "no problems, slight problems, moderate problems, severe problems, and unable to do/extreme" [8-10].

In many countries, this questionnaire is applied to evaluate population health status for which population

Table 1 Sociodemographic characteristics of the sample $(N=3060)$

\begin{tabular}{|c|c|c|c|c|}
\hline \multirow[t]{2}{*}{ Variable } & & \multicolumn{2}{|c|}{ Study sample } & \multirow{2}{*}{$\begin{array}{l}\text { Tehran adult population [14] } \\
\%\end{array}$} \\
\hline & & $\bar{n}$ & $\%$ & \\
\hline \multirow[t]{2}{*}{ Gender } & Male & 1506 & 49.2 & 49.8 \\
\hline & female & 1555 & 50.8 & 50.2 \\
\hline \multirow[t]{6}{*}{ Age (year) } & $<30$ & 609 & 19.8 & 31.7 \\
\hline & $30-39$ & 726 & 23.7 & 22.6 \\
\hline & $40-49$ & 602 & 19.7 & 18.2 \\
\hline & $50-59$ & 539 & 17.6 & 13.7 \\
\hline & $60-69$ & 389 & 12.7 & 7.7 \\
\hline & $>69$ & 195 & 6.37 & 6.1 \\
\hline \multirow[t]{5}{*}{ Education level } & Illiterate & 140 & 4.6 & 6.7 \\
\hline & Elementary & 387 & 12.6 & 15.4 \\
\hline & Guidance & 516 & 16.9 & 16.1 \\
\hline & High school and pre-university & 1100 & 35.9 & 33.2 \\
\hline & University & 917 & 30.0 & 28.5 \\
\hline \multirow[t]{6}{*}{ Employment status } & Employed & 1079 & 35.3 & 38.7 \\
\hline & Student & 221 & 7.2 & 7.6 \\
\hline & Homemaker & 1239 & 40.5 & 32.1 \\
\hline & Retired & 395 & 12.9 & 10.5 \\
\hline & Unemployed & 100 & 3.3 & 5.9 \\
\hline & Others & 22 & 0.7 & 5.3 \\
\hline \multirow[t]{3}{*}{ Marital status } & Never married & 549 & 18.0 & 23.5 \\
\hline & Married & 2358 & 77.3 & 68.6 \\
\hline & Divorce or widowed & 144 & 4.7 & 8.0 \\
\hline \multicolumn{5}{|l|}{ Experience of a serious illness } \\
\hline \multirow[t]{2}{*}{ In self } & Yes & 319 & 10.4 & \\
\hline & No & 2737 & 89.6 & \\
\hline \multirow[t]{2}{*}{ In family } & Yes & 551 & 18.0 & \\
\hline & No & 2505 & 82.0 & \\
\hline \multirow[t]{2}{*}{ In caring for others } & Yes & 484 & 15.9 & \\
\hline & No & 2562 & 84.1 & \\
\hline \multirow[t]{2}{*}{ Presence of any illness or health problem } & Yes & 1115 & 36.5 & \\
\hline & No & 1945 & 63.5 & \\
\hline \multirow[t]{5}{*}{ Health status } & Excellent & 253 & 8.3 & \\
\hline & Very good & 462 & 15.1 & \\
\hline & Good & 1476 & 48.2 & \\
\hline & Fair & 753 & 24.6 & \\
\hline & Poor & 115 & 3.8 & \\
\hline
\end{tabular}


norms are derived. The utility scores are extracted by gender, age, and other sociodemographic characteristics $[9,11,12]$. These studies provide the requisitions for health status surveillance and wider economic evaluations.

Although the three level EQ-5D utility scores for Iran are calculated by a previous study [13], as yet the HRQoL scores of general population based on
EQ-5D-5 L is not reported. The current study aimed at providing the HRQoL scores and their determinants among the adult population of Tehran. The results improve the knowledge of the policy makers about the HRQoL of Tehran population and characteristics associated with their general health states to facilitate decision making, and health economic evaluations studies in Iran.

a

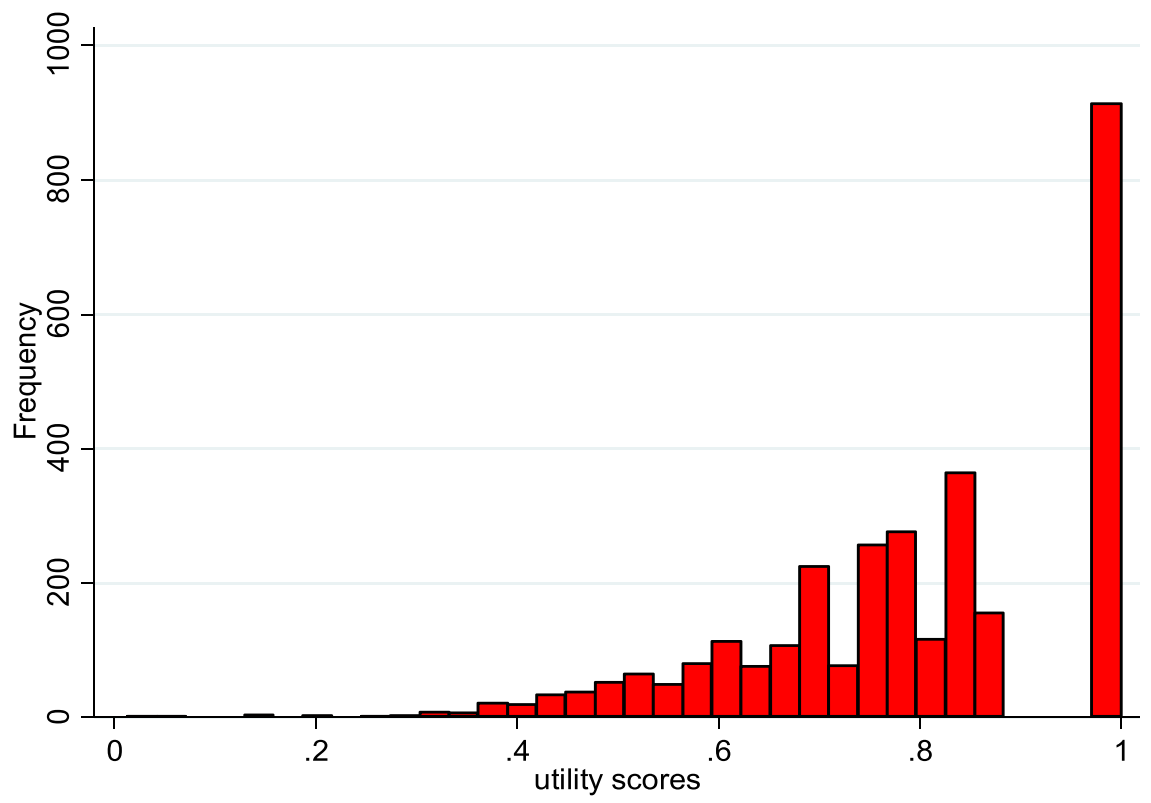

b

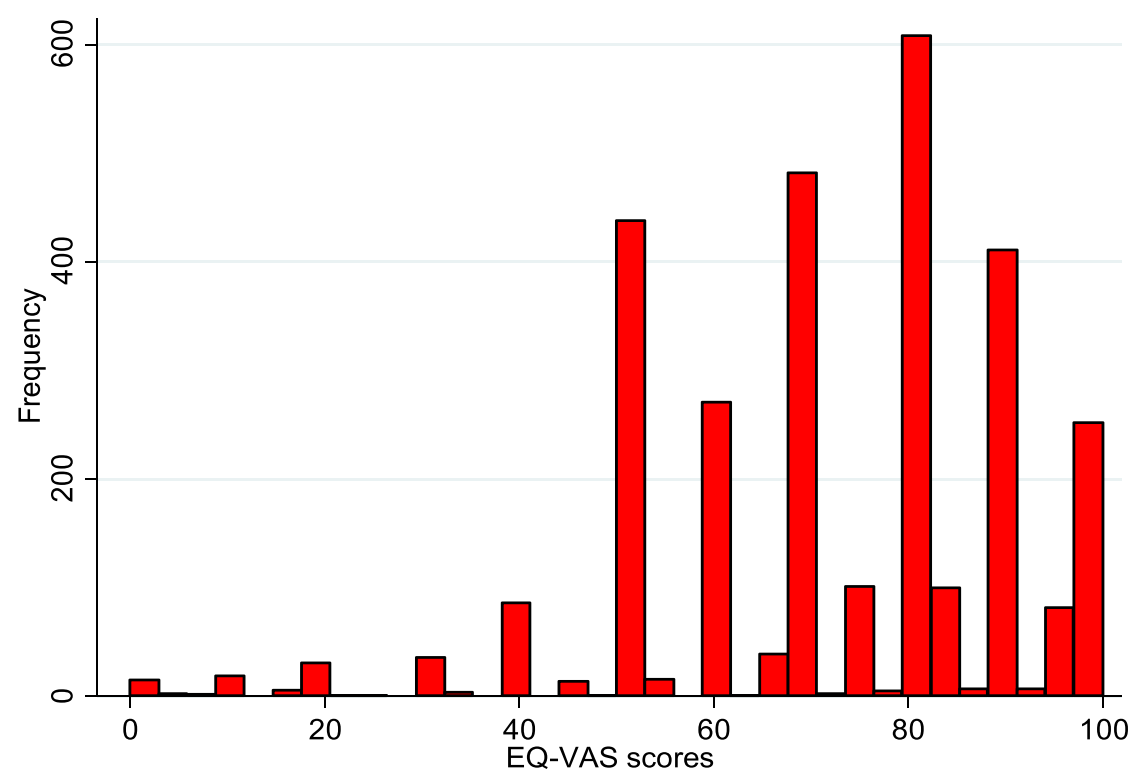

Fig. 1 a. Distribution of the health-related quality of life Scores, $\mathbf{b}$. Distribution of EQ-VAS Scores 


\section{Materials and methods}

The current cross-sectional observational study was conducted on 3060 individuals in Tehran (the capital city of Iran) with the minimum age of 18, from October 2015 to March 2016. They were selected by a stratified random sampling method. First, Tehran population was divided into 22 municipal districts. Each district was divided into several blocks. Some blocks were randomly selected in each district. Number of selected blocks was determined according to the population of each district, and 300 blocks were totally selected for data collection. In each block, 10 households were randomly selected for interview. The respondents were selected by quota sampling in proportion to their basic social-demographic characteristics (gender, age) to be a representative sample of the Tehran adult population according to the data from the most recent census (Table 1). The households with non-responses were replaced with households in the replacement list. The interviews were conducted face-to-face by some trained interviewers.

\section{Data collection}

Data was collected using a questionnaire with three main parts. The first section comprised demographic questions about age, gender, education level, employment status, and marital status. These questions were according to the demographic part of a questionnaire provided by the Statistical Center of Iran (SCI), for the national population and housing census [14]. The second part was regarding the

Table 2 Mean EQ-5D-5 L utility scores by sociodemographic characteristics

\begin{tabular}{|c|c|c|c|c|c|c|c|c|c|}
\hline \multirow[t]{2}{*}{ Variable } & \multicolumn{3}{|l|}{ Total } & \multicolumn{3}{|l|}{ Males } & \multicolumn{3}{|l|}{ Females } \\
\hline & number & Mean & Std.Dev. & number & Mean & $\overline{\text { Std.Dev. }}$ & Number & Mean & Std.Dev. \\
\hline All & 3060 & 0.79 & 0.17 & 1505 & 0.83 & 0.16 & 1555 & 0.76 & 0.17 \\
\hline
\end{tabular}

$Z=11.473, p<0.001$

Age category, years

$<30$
$30-39$
$40-49$
$50-59$
$60-69$
$>69$
Total

609
726
602
539
389
195

$\begin{array}{ll}0.87 & 0.12 \\ 0.83 & 0.15 \\ 0.78 & 0.15 \\ 0.75 & 0.17 \\ 0.74 & 0.18 \\ 0.67 & 0.20 \\ X^{2}=291.367, & p<0.001\end{array}$

341
342
252
234
207
129

0.88
0.85
0.83
0.81
0.79
0.70

$\begin{array}{ll}0.12 & 268 \\ 0.14 & 384 \\ 0.14 & 350 \\ 0.16 & 305 \\ 0.18 & 182 \\ 0.20 & 66\end{array}$

$\begin{array}{ll}0.86 & 0.12 \\ 0.81 & 0.15 \\ 0.75 & 0.15 \\ 0.71 & 0.16 \\ 0.68 & 0.17 \\ 0.61 & 0.19\end{array}$

\section{Education level}

\begin{tabular}{|c|c|c|c|c|c|c|c|c|c|}
\hline Illiterate & 140 & 0.68 & 0.22 & 52 & 0.73 & 0.23 & 88 & 0.64 & 0.20 \\
\hline Elementary & 387 & 0.73 & 0.18 & 141 & 0.76 & 0.20 & 246 & 0.71 & 0.17 \\
\hline Secondary & 516 & 0.76 & 0.17 & 256 & 0.81 & 0.16 & 260 & 0.72 & 0.16 \\
\hline High & 1100 & 0.81 & 0.15 & 507 & 0.84 & 0.15 & 593 & 0.78 & 0.15 \\
\hline University & 917 & 0.84 & 0.14 & 549 & 0.86 & 0.14 & 368 & 0.82 & 0.14 \\
\hline Total & & \multicolumn{8}{|c|}{$X^{2}=172.145, p<0.001$} \\
\hline \multicolumn{10}{|l|}{ Employment status } \\
\hline Employed & 1079 & 0.84 & 0.14 & 936 & 0.85 & 0.14 & 143 & 0.79 & 0.15 \\
\hline Student & 221 & 0.88 & 0.11 & 135 & 0.89 & 0.10 & 86 & 0.87 & 0.13 \\
\hline Homemaker & 1239 & 0.75 & 0.17 & 4 & 0.72 & 0.27 & 1235 & 0.75 & 0.17 \\
\hline Retired & 395 & 0.76 & 0.18 & 341 & 0.76 & 0.18 & 54 & 0.76 & 0.18 \\
\hline Unemployed & 100 & 0.82 & 0.17 & 66 & 0.79 & 0.18 & 34 & 0.88 & 0.11 \\
\hline Other & 22 & 0.71 & 0.26 & 21 & 0.71 & 0.27 & 1 & 0.63 & 0.00 \\
\hline Total & & \multicolumn{8}{|c|}{$X^{2}=251.442, p<0.001$} \\
\hline \multicolumn{10}{|l|}{ Marital status } \\
\hline Never married & 549 & 0.87 & 0.13 & 387 & 0.87 & 0.12 & 162 & 0.86 & 0.13 \\
\hline Married & 2358 & 0.78 & 0.17 & 1082 & 0.81 & 0.17 & 1276 & 0.76 & 0.16 \\
\hline Divorce or widowed & 144 & 0.67 & 0.17 & 27 & 0.71 & 0.16 & 117 & 0.66 & 0.17 \\
\hline Total & & \multicolumn{8}{|c|}{$X^{2}=178.314, p<0.001$} \\
\hline
\end{tabular}


general health status questions about the respondent's viewpoints of his/her health and the presence of any illness or health problem in respondents or their family members. Health status was measured by a categorical measure. In the categorical health rating question, individuals rated their own current health status on a 5-point scale (excellent, very good, good, fair, or poor). The presence of any illness or health problem was assessed with the question: "Do you have any illness, health problem, condition, or disability?". The third part consisted of the official Iranian version of the EQ-5D-5 L. The EQ-5D-5 L consists of two pages: the descriptive system and the Visual Analogue Scale (EQVAS). The EQ-5D-5 L descriptive system consists of five dimensions as follows: mobility (MO), self-care (SC), usual activities (UA), pain/discomfort (PD), and anxiety/ depression $(\mathrm{AD})$. Each dimension in the EQ-5D-5 L has five response levels: no problems (Level 1); slight; moderate; severe; and extreme problems (Level 5). Total 3125 (55) health states are defined for EQ-5D-5 L. Health states are from 11,111 (the best health state) to 55,555 (the worst health state). EQ-5D-5 L health states are converted into a single index 'utility' score using a scoring algorithm based on public preferences. The instrument also includes a visual analogue scale (EQ-VAS) which provides a single global rating of self-perceived health and is scored on a 0 to 100 $\mathrm{mm}$ scale representing "the worst ..." and "the best health you can imagine", respectively.

\section{Data analysis}

To measure the respondents' HRQoL scores according to the EQ-5D-5 L questionnaire, since a standard EQ-5D-5 L value set was not available for Iran, the five-level crosswalk-based value set derived from the EQ-5D-3 L value set in Iran was used [13, 15]. A crosswalk-based value set is an interim scoring method for the EQ-5D-5 L that allows EQ-5D-5 L values to be derived from any existing EQ-5D-3 L value set. The crosswalk is based on a response mapping approach that estimates the relationship between responses to the EQ-5D-3 L ('3 L') and EQ-5D-5 L ('5 L') descriptive systems, and subsequently establishes a link to the established $3 \mathrm{~L}$ value sets [16]. The crosswalk methodology developed by van Hout et al. [16], was applied to the Iran EQ-5D-3 L value set [13] developed using a face-to-face TTO method to obtain the Iran crosswalk EQ-5D-5 L value set.

Descriptive summary statistics were estimated for sociodemographic variables, the EQ-5D-5 L dimensions, utility scores, and self-reported health status. The distribution of answers to the questions in the descriptive part of the EQ-5D-5 L was estimated for the whole sample, as well as for the different age groups. To assess the mean EQ-5D-5L score differences between sociodemographic groups, the Wilcoxon rank-sum test (for variables with two sub-groups) and the Kruskal-Wallis test (for variables with multiple sub-groups) were applied [17, 18].

The Generalized linear model (GLM) was employed to explore (understand) the association between sociodemographic variables and EQ-5D utility scores (model 1) as well as VAS scores (model 2). This model is able to control skewness and heteroscedasticity. We used GLM model with a Poisson distribution and a log link, which requires none-negative values. Therefore disutility value (disutility $=1$-utility value) was entered as the dependent variable $[17,19]$. The analyses were conducted using STATA version 13.

\section{Results}

Table 1 shows the descriptive statistics of the variables. The response rate was about $70 \%$. In the current study, $51 \%$ of the participants were female; the mean \pm standard deviation (SD) of the participants' age was $44 \pm$ 15.6 years; about $63 \%$ of the participants were younger

Table 3 Mean EQ-VAS Scores by gender and age

\begin{tabular}{|c|c|c|c|c|c|c|c|c|c|}
\hline \multirow[t]{2}{*}{ Variable } & \multicolumn{3}{|l|}{ Total } & \multicolumn{3}{|l|}{ Males } & \multicolumn{3}{|l|}{ Females } \\
\hline & number & Mean & Std.Dev. & number & Mean & $\overline{\text { Std.Dev. }}$ & number & Mean & Std.Dev \\
\hline All & 3042 & 71.7 & 19.37 & 1498 & 73.77 & 18.67 & 1544 & 69.74 & 19.83 \\
\hline \multicolumn{10}{|c|}{$Z=5.696, p<0.001$} \\
\hline \multicolumn{10}{|c|}{ Age category, years } \\
\hline$<30$ & 607 & 79.9 & 15.8 & 340 & 80.0 & 16.3 & 267 & 79.8 & 15.1 \\
\hline $30-39$ & 723 & 75.1 & 17.1 & 341 & 76.1 & 16.5 & 382 & 74.2 & 17.6 \\
\hline $40-49$ & 599 & 70.2 & 17.7 & 252 & 73.0 & 16.5 & 347 & 68.2 & 18.3 \\
\hline $50-59$ & 535 & 66.8 & 20.9 & 232 & 70.6 & 20.3 & 303 & 63.8 & 20.9 \\
\hline $60-69$ & 386 & 66.7 & 20.8 & 205 & 70.2 & 20.1 & 181 & 62.6 & 20.9 \\
\hline$>69$ & 192 & 61.8 & 22.5 & 128 & 63.9 & 21.7 & 64 & 57.5 & 23.6 \\
\hline Total & & \multicolumn{8}{|c|}{$X^{2}=242.371, p<0.001$} \\
\hline
\end{tabular}

Wilcoxon rank-sum test and Kruskal-Wallis test run for VAS scores 
than 50 years old; and the average education years was $10.8 \pm 4.8$. In other words, $4.6 \%$ of the participants were illiterate, about $70 \%$ had high school diploma or lower, and $30 \%$ had a university education. Most of the participants were homemaker (40.5\%); $35.5 \%$ were unemployed, but had income, and $7.6 \%$ were students; $77.3 \%$ of the subjects were married (had spouse), $18 \%$ were single (never married), and $4.7 \%$ were divorced or widowed.

Approximately, $10.4 \%$ of the participants experienced a serious illness, and $36.5 \%$ of them had illness or health problem. The results of self-rated health status show that $23 \%$ of the participants' health status was "excellent" or "very good", while $4 \%$ was "poor".

The health status of the participants according to the dimensions of the EQ-5D-5 L questionnaire is reported in the Additional file 1 . About $70.5 \%$ of the individuals had no problems in walking, while $0.1 \%$ were unable to walk; $90.6 \%$ of the participants had no problems washing or dressing himself/herself, while $0.1 \%$ were unable; $76.3 \%$ of the individuals had no problems doing his/her usual activities, while $0.3 \%$ were unable; $46.7 \%$ of the participants had no pain or discomfort, while $0.8 \%$ had

Table 4 GLM poisson regression to determine the effective factors on the health related quality of life disutility scores and EQ-VAS scores

\begin{tabular}{|c|c|c|c|c|c|c|}
\hline \multirow[t]{3}{*}{ Independent variable } & \multicolumn{3}{|c|}{ Dependent variable: disutility scores } & \multicolumn{3}{|c|}{ Dependent variable: EQ-VAS scores } \\
\hline & \multicolumn{3}{|l|}{ Model 1} & \multicolumn{3}{|l|}{ Model 2} \\
\hline & Coefficient & $p$-value & $95 \% \mathrm{Cl}$ & Coefficient & $p$-value & $95 \% \mathrm{Cl}$ \\
\hline \multicolumn{7}{|l|}{ Gender } \\
\hline Male & Ref & & & & & \\
\hline Female & 0.215 & 0.164 & $-0.088,0.519$ & -0.014 & 0.054 & $-0.028,0.000$ \\
\hline \multicolumn{7}{|l|}{ Age category } \\
\hline$<30$ & Ref & & & & & \\
\hline $30-39$ & 0.226 & 0.178 & $-0.103,0.555$ & -0.050 & 0.000 & $-0.064,-0.035$ \\
\hline $40-49$ & 0.416 & 0.016 & $0.076,0.756$ & -0.106 & 0.000 & $-0.122,-0.090$ \\
\hline $50-59$ & 0.494 & 0.006 & $0.143,0.844$ & -0.139 & 0.000 & $-0.156,-0.122$ \\
\hline $60-69$ & 0.547 & 0.005 & $0.161,0.932$ & -0.144 & 0.000 & $-0.164,-0.124$ \\
\hline$>69$ & 0.785 & 0.001 & $0.334,1.236$ & -0.208 & 0.000 & $-0.235,-0.182$ \\
\hline \multicolumn{7}{|l|}{ Marital status } \\
\hline Never married & Ref & & & & & \\
\hline Married & 0.053 & 0.749 & $-0.275,0.383$ & 0.014 & 0.046 & $0.000,0.029$ \\
\hline Divorced or widowed & 0.223 & 0.338 & $-0.233,0.679$ & -0.107 & 0.000 & $-0.134,-0.080$ \\
\hline \multicolumn{7}{|l|}{ Employment status } \\
\hline Employed & Ref & & & & & \\
\hline Student & -0.032 & 0.897 & $-0.526,0.461$ & 0.009 & 0.355 & $-0.010,0.028$ \\
\hline Home maker & 0.149 & 0.381 & $-0.185,0.484$ & -0.039 & 0.000 & $-0.055,-0.022$ \\
\hline Retired & 0.093 & 0.553 & $-0.214,0.400$ & 0.007 & 0.397 & $-0.009,0.025$ \\
\hline Unemployed & 0.152 & 0.563 & $-0.364,0.670$ & 0.007 & 0.545 & $-0.017,0.032$ \\
\hline Others & 0.569 & 0.164 & $-0.232,1.372$ & -0.213 & 0.000 & $-0.268,-0.0158$ \\
\hline \multicolumn{7}{|l|}{ Education } \\
\hline Illiterate & Ref & & & & & \\
\hline Elementary & -0.010 & 0.957 & $-0.377,0.357$ & 0.017 & 0.192 & $-0.008,0.043$ \\
\hline Guidance & -0.073 & 0.692 & $-0.436,0.290$ & 0.042 & 0.001 & $0.017,0.067$ \\
\hline High school and pre-university & -0.159 & 0.386 & $-0.519,0.200$ & 0.078 & 0.000 & $0.053,0.102$ \\
\hline University & -0.208 & 0.293 & $-0.598,0.180$ & 0.094 & 0.000 & $0.068,0.120$ \\
\hline Constant & -2.115 & 0.000 & $-2.607,-1.622$ & 4.307 & 0.000 & $4.279,4.335$ \\
\hline AIC & 0.899 & & & 11.590 & & \\
\hline $\mathrm{BIC}$ & $-23,823.73$ & & & -7364.766 & & \\
\hline
\end{tabular}


extreme pain or discomfort. Considering the "anxiety/ depression", $46 \%$ of the individuals stated no anxiety or depression, while $2.1 \%$ were extremely anxious or depressed.

Figure 1 shows the participants' HRQoL (utilities) and EQ-VAS scores. The HRQoL scores were left-skewed. They ranged from 0.013 to 1 . The mean HRQoL score was $0.79 \pm 0.17$. The EQ-VAS scores ranged from 0 to 100. The mean EQ-VAS score was $71.7 \pm 19.4$.

Table 2 shows the mean EQ-5D-5L utility scores by sociodemographic characteristics. The mean utility scores range $0.61 \pm 0.19$ in $>69$ year-old females to $0.88 \pm 0.12$ in $<30$ year-old males. Table 3 shows the mean EQ-VAS scores by gender and age groups. The mean VAS scores range $57.5 \pm 23.6$ in $>69$ year-old females to $80 \pm 16.3$ in $<30$ year-old males.

Men had higher scores than women. The average score of men was $0.83 \pm 0.16$ while the average score of women was $0.76 \pm 0.17$. The mean VAS score was $73 \pm$ 18 for men versus $69 \pm 19$ for women. Both EQ-5D and EQ-VAS scores reduced with age increase. The EQ-5D utility scores shows significant difference in all groups of socio-demographic characteristics, including educational level employment status and marital status.

Table 4 shows the results of the regression model. In the first model the relationships were not significant about most of the factors. Although, in the second model, there was a significant relationship between gender and the VAS scores; on average, scores were lower in females than males. The VAS scores reduced with age increase; the higher educational level led to higher scores. The VAS scores among individuals without spouse (divorced or widowed) were significantly lower than those of the married individuals or the never married ones. The VAS scores were lower in homemakers than the others.

\section{Discussion}

The current study provided the EQ-5D-5L utility scores and EQ-VAS and their determinants among the adult population of Tehran. About 71, 91, 76, 47, and $46 \%$ of the participants reported no problems on mobility, self-care, usual activities, pain/discomfort, and anxiety/depression, respectively. The HRQoL mean score was $0.79 \pm 0.17$ based on crosswalk method. The VAS mean score was $71.7 \pm 19$.4. Considering EQ-VAS scores gender, age, education status, marital status, and employment status were associated withHRQoL.

In a previous study by Goudarzi et al. in Iran, using the three level questionnaire, the percentages of individuals reporting no problems on mobility, self-care, usual activities, pain/discomfort, and anxiety/depression were $89,99,96,66$, and $67 \%$, respectively [13]. These figures were measured as $71,91,76,47$, and $46 \%$ in the present study, respectively. The ratios were very similar in each dimension. For example, in both studies the majority of people had no problems in self-care. Moreover, individuals had problems with anxiety/depression, and pain/discomfort more than the other dimensions. However, in the current study, the percentage of individuals with "no problems" was less than that of the previous study in all dimensions. It might be due to the higher sensitivity and the lower "ceiling effect" of the EQ-5D-5 L compared with the EQ-5D-3 L questionnaire [20-22].

The Iranian participants reporting no problems were lower than those of some other countries such as South Australia, Poland, Italy, and Germany. This issue was observed in all the dimensions, which was notably prominent in "anxiety/depression" dimension. The percentage of individuals with no anxiety or depression was $46 \%$ in Iran, which was 73.3, 58.5, 61.7 and $77.4 \%$ in South Australia, Poland, Italy, and Germany, respectively [11, 12, 17, 23].

It is interesting to note that in anxiety/depression and pain/discomfort dimensions the individuals mainly had moderate problems, which was true in all age groups. While in other dimensions, more than half of the sample had no problems in lower age groups and the percentage of individuals with problems increased in higher age groups. It was consistent with the finding of other countries $[11,12,17]$. High percentage of the anxiety/depression in all ages is a sign that highlights the risk of the psychological disorders, which requires purposeful considerations and measures.

The mean utility score of the current study participants $(0.79 \pm 0.17)$ seems lower than those of Germany (0.92) [23], South Australia (0.91) [17], Poland (0.89) [11], Uruguay (0.95) [24], and Italy (0.92) [12]; and was very similar to the previously reported value $(0.79)$ using the three level version in an adult sample of Tehran [15]. This likeness arise from the studies' population and value set similarities.

The study showed that females had lower utility scores than males. Goudarzi et al., indicated that in all dimensions, females had more problems than males [13], which was also confirmed by other studies [25, 26].

The regression analyses represented that male, younger, and more educated individuals were more probable to have a better EQ-VAS scores, which coincided with the findings of other countries [17,27,28].

The VAS score of single subjects (divorced or widowed) was significantly lower than those of the married or never married ones. Recently, the divorce rate increased in Iran. The marriage to divorce ratio was 16 in 1993, which reduced to 4.4 in 2014 [29]. Due to the problems that families might face, in addition to the families' HRQoL reduction due to divorce or the spouse 
death [30], effective interventions are needed to strengthen the families, reduce divorce, and support such vulnerable groups.

The current study for the first time applied the EQ$5 \mathrm{D}-5 \mathrm{~L}$ in a large sample in Tehran. Tehran is a highly populated city (consisting 11\% of Iran population) and consists of different ethnic groups, which can be a proper representative for Iran community.

\section{Conclusion}

The current study provided HRQoL scores and their determinants for the Iranian adult population, which was applicable for the policy makers. In fact, having an accurate perspective of the society health status helps the planners and policy makers in decision making. Since more than half of the subjects described their health status moderately or extremely anxious or depressed, it is recommended that more attention be paid to the spiritual morbidities and effective intervention be implemented to prevent such diseases. Due to the relatively low utility scores of the Iranians, long term planning is required to increase their health scores, especially for the vulnerable groups of the community.

\section{Supplementary information}

Supplementary information accompanies this paper at https://doi.org/10. 1186/s12955-020-01365-5.

\section{Additional file 1}

\section{Abbreviations}

HRQoL: Health-Related Quality of Life; QoL: Quality of Life; VAS: Visual Analog Scale

\section{Acknowledgements}

Not applicable.

\section{Authors' contributions}

All authors contributed to the study conception and design. Material preparation, data collection and analysis were performed by Ali Akbari Sari, Zahra Emrani, Hojjat Zeraati, Alireza Oliyaeemanesh, and Rajabali Daroudi. The first draft of the manuscript was written by Rajabali Daroudi and Zahra Emrani and all authors commented on previous versions of the manuscript. All authors read and approved the final manuscript.

\section{Authors' information}

Not applicable.

\section{Funding}

This study was funded by Tehran University of Medical Sciences (grant number 94-01-159-28771).

\section{Availability of data and materials}

The datasets used and/or analyzed during the current study are available from the corresponding author on reasonable request.

\section{Ethics approval and consent to participate}

This study was approved by the ethics committee of the Deputy of Research and Technology of the Tehran University of Medical Sciences

(IR.TUMS.REC.1394.743). The participants were assured that their information would remain confidential. Informed consent was obtained from all individual participants included in the study.
Consent for publication

Not applicable.

\section{Competing interests}

The authors declare they have no conflict of interests.

\section{Author details}

${ }^{1}$ Department of Health Management and Economics, School of Public Health, Tehran University of Medical Sciences, Poursina Ave, Tehran 1417613191, Iran. ${ }^{2}$ Department of Epidemiology and Biostatistics, Tehran University of Medical Sciences, Tehran, Iran. ${ }^{3}$ National Institute for Health Research \& Health Equity Research Centre, Tehran University of Medical Sciences, Tehran, Iran.

Received: 29 September 2019 Accepted: 15 April 2020

Published online: 25 April 2020

\section{References}

1. Karimi M, Brazier J. Health, health-related quality of life, and quality of life: what is the difference? Pharmacoeconomics. 2016:34:645-9.

2. Brazier J, Ara R, Rowen D, Chevrou-Severac H. A review of generic preference-based measures for use in cost-effectiveness models. Pharmacoeconomics. 2017;35:21-31.

3. Saarni Sl, Härkänen T, Sintonen H, Suvisaari J, Koskinen S, Aromaa A, et al. The impact of 29 chronic conditions on health-related quality of life: a general population survey in Finland using 15D and EQ-5D. Qual Life Res. 2006;15:1403-14.

4. Janssen MF, Bonsel GJ, Luo N. Is EQ-5D-5L better than EQ-5D-3L? A headto-head comparison of descriptive systems and value sets from seven countries. Pharmacoeconomics. 2018;36:675-97.

5. Kim SH, Kim HJ, Lee S-i, Jo M-W. Comparing the psychometric properties of the EQ-5D-3L and EQ-5D-5L in cancer patients in Korea. Qual Life Res. 2012; 21:1065-73.

6. Conner-Spady BL, Marshall DA, Bohm E, Dunbar MJ, Loucks L, Al Khudairy A, et al. Reliability and validity of the EQ-5D-5L compared to the EQ-5D-3L in patients with osteoarthritis referred for hip and knee replacement. Qual Life Res. 2015;24:1775-84.

7. Poór AK, Rencz F, Brodszky V, Gulácsi L, Beretzky Z, Hidvégi B, et al. Measurement properties of the EQ-5D-5L compared to the EQ-5D-3L in psoriasis patients. Qual Life Res. 2017;26:3409-19.

8. Johnson JA, Luo N, Shaw JW, Kind P, Coons SJ. Valuations of EQ-5D health states: are the United States and United Kingdom different? Med Care. 2005: 221-8.

9. Yang Z, Busschbach J, Liu G, Luo N. EQ-5D-5L norms for the urban Chinese population in China. Health Qual Life Outcomes. 2018;16:210.

10. Agborsangaya CB, Lahtinen M, Cooke T, Johnson JA. Comparing the EQ-5D $3 \mathrm{~L}$ and $5 \mathrm{~L}$ : measurement properties and association with chronic conditions and multimorbidity in the general population. Health Qual Life Outcomes. 2014;12:74.

11. Golicki D, Niewada M. EQ-5D-5L polish population norms. Arch Med Sci. 2017;13:191.

12. Scalone L, Cortesi PA, Ciampichini R, Cesana G, Mantovani LG. Health related quality of life norm data of the Italian general population: results using the EQ-5D-3L and EQ-5D-5L instruments. Epidemiol Biostat Public Health. 2015:12:e11457.

13. Goudarzi R, Sari AA, Zeraati H, Rashidian A, Mohammad K, Amini S. Valuation of quality weights for EuroQol 5-dimensional health states with the time trade-off method in the Capital of Iran. Value Health Reg Issues. 2019:18:170-5.

14. Statistical Center of Iran. Population and Housing Censuses. 2016 [cited 2020]. Available from: https://www.amar.org.ir/english/Population-andHousing-Censuses.

15. Goudarzi R, Zeraati H, Sari AA, Rashidian A, Mohammad K. Population-based preference weights for the EQ-5D health states using the visual analogue scale (VAS) in Iran. Iran Red Crescent Med J. 2016;18:e21584.

16. van Hout B, Janssen M, Feng Y-S, Kohlmann T, Busschbach J, Golicki D, et al. Interim scoring for the EQ-5D-5L: mapping the EQ-5D-5L to EQ-5D-3L value sets. Value Health. 2012;15:708-15.

17. McCaffrey N, Kaambwa B, Currow DC, Ratcliffe J. Health-related quality of life measured using the EQ-5D-5L: south Australian population norms. Health Qual Life Outcomes. 2016;14:133. 
18. Kontodimopoulos N, Pappa E, Niakas D, Yfantopoulos J, Dimitrakaki C, Tountas Y. Validity of the EuroQoL (EQ-5D) instrument in a Greek general population. Value Health. 2008;11:1162-9.

19. Nguyen $L H$, Tran BX, Le QN, Tran TT, Latkin CA. Quality of life profile of general Vietnamese population using EQ-5D-5L. Health Qual Life Outcomes. 2017;15:199.

20. Herdman M, Gudex C, Lloyd A, Janssen M, Kind P, Parkin D, et al. Development and preliminary testing of the new five-level version of EQ-5D (EQ-5D-5L). Qual Life Res. 2011;20:1727-36.

21. Janssen M, Pickard AS, Golicki D, Gudex C, Niewada M, Scalone L, et al. Measurement properties of the EQ-5D-5L compared to the EQ-5D-3L across eight patient groups: a multi-country study. Qual Life Res. 2013;22:1717-27.

22. Richardson J, Khan MA, lezzi A, Maxwell A. Comparing and explaining differences in the magnitude, content, and sensitivity of utilities predicted by the EQ-5D, SF-6D, HUI 3, 15D, QWB, and AQoL-8D multiattribute utility instruments. Med Decis Mak. 2015;35:276-91.

23. Hinz A, Kohlmann T, Stöbel-Richter Y, Zenger M, Brähler E. The quality of life questionnaire EQ-5D-5L: psychometric properties and normative values for the general German population. Qual Life Res. 2014;23:443-7.

24. Augustovski F, Rey-Ares L, Irazola V, Garay OU, Gianneo O, Fernández G, et al. An EQ-5D-5L value set based on Uruguayan population preferences. Qual Life Res. 2016;25:323-33.

25. Tajvar M, Arab M, Montazeri A. Determinants of health-related quality of life in elderly in Tehran, Iran. BMC Public Health. 2008;8:323.

26. Hoi LV, Chuc NT, Lindholm L. Health-related quality of life, and its determinants, among older people in rural Vietnam. BMC Public Health. 2010;10:549.

27. Hoeymans N, Van Lindert H, Westert G. The health status of the Dutch population as assessed by the EQ-6D. Qual Life Res. 2005;14:655-63.

28. Purba FD, Hunfeld JA, Iskandarsyah A, Fitriana TS, Sadarjoen SS, Passchier J, et al. Quality of life of the Indonesian general population: test-retest reliability and population norms of the EQ-5D-5L and WHOQOL-BREF. PLOS One. 2018:13:e0197098.

29. Gholipour HF, Farzanegan MR. Marriage crisis and housing costs: empirical evidence from provinces of Iran. J Policy Model. 2015;37:107-23.

30. Aghajanian A, Thompson V. Recent divorce trend in Iran. J Divorce Remarriage. 2013;54:112-25.

\section{Publisher's Note}

Springer Nature remains neutral with regard to jurisdictional claims in published maps and institutional affiliations.

Ready to submit your research? Choose BMC and benefit from:

- fast, convenient online submission

- thorough peer review by experienced researchers in your field

- rapid publication on acceptance

- support for research data, including large and complex data types

- gold Open Access which fosters wider collaboration and increased citations

- maximum visibility for your research: over $100 \mathrm{M}$ website views per year

At BMC, research is always in progress.

Learn more biomedcentral.com/submissions 